\title{
FORECASTING FINANCIAL CYCLES: CAN BIG DATA HELP?
}

\author{
Marinko ŠKARE ${ }^{1 *}$, Małgorzata PORADA-ROCHOŃ ${ }^{2}$ \\ ${ }^{1}$ Faculty of Economics and Tourism "Dr. Mijo Mirkovic", Juraj Dobrila University of Pula, Pula, Croatia \\ ${ }^{2}$ Faculty of Economics, Finance and Management, University of Szczecin, Szczecin, Poland
}

Received 10 November 2019; accepted 19 April 2020

\begin{abstract}
Financial cycles as a source of financial crisis and business cycles that was demonstrated during the financial crisis of 2008, so it is important to understand proper methods of measuring and forecasting them to unravel their true nature. We searched financial big data for the UK, USA, Japan and China for a period 2004Q1 to 2019Q1 to find important data corresponding to the research and determine their importance for the financial cycle studies. We use singular spectral analysis (SSA without financial big data) and multichannel singular spectral analysis (MSSA with financial big data) to identify significant deterministic cycles in the residential property prices, credits to private non-financial sector and credit share in the GDP. The forecast test results show on the data for the UK, USA, Japan and China that inclusion of the financial big data significantly (on the level from $30 \%$ to four times) improves forecast accuracy for financial cycle components. This is a first study on the importance of the link between financial cycles and financial big data. Policymakers, practitioners and financial cycles research should take into the account the importance of financial big data for the studies of financial cycles for a better understanding of their true nature and improving their forecast accuracy.
\end{abstract}

Keywords: financial cycles, big data, forecast accuracy, singular spectral analysis, multichannel singular spectral analysis, time series.

JEL Classification: G2, G3, O16, C58.

\section{Introduction}

The global financial crisis of 2008 after decades of the great moderation policy governance opened the discussion of the financial stability importance for economic activity. Identification of the earning warning signals to predict business cycles and avoid instability in the economy was always the primary goal of the policymakers. Our paper is the first to combine financial big data to forecast financial cycles.

First to mention the importance of the big data for macroeconomic management was (Phillips, 1962). Phillips (1962) put forward the assumption that policymakers can not design effective economic policy without quantitative knowledge behind the main economic

\footnotetext{
*Corresponding author. E-mail: mskare@unipu.hr
}

\section{(c) 2020 The Author(s). Published by VGTU Press}

This is an Open Access article distributed under the terms of the Creative Commons Attribution License (http://creativecommons. $\mathrm{org} / \mathrm{licenses} / \mathrm{by} / 4.0 /$ ), which permits unrestricted use, distribution, and reproduction in any medium, provided the original author and source are credited. 
forces governing the economic system. Main economic forces comprise employment, inflation and growth as instruments and policy goals at the same time. Therefore, it is not possible to design an optimal economic policy without knowing the quantitative relations that hold between these economic forces. To measure and identify the correct quantitive relationship among employment, inflation and growth, a big data approach is essential.

Fluctuations in financial variables always had a significant impact on real economic activities. That is the case today but was all the same 3000 years ago. Oscillatory behaviour in savings and investments dynamics and price targeting articulate economic cycle, see Ji Ran (Milburn, 2007). Policymakers must always monitor the saving-investments cycle keeping prices under control to ensure the smooth running of the economy. The same concept highlighting the importance of financial conditions for business cycles is extended in (Keynes, 1936; Schumpeter, 1939; Minsky, 1963, 1975).

Inherent dynamics in financial conditions articulate the dynamics of the business cycles driving economic booms and downturns. Financial markets offer many financial data reflecting financial conditions still financial cycles definition, measurement and forecasting remain undisclosed. We can understand the complexity of the problem from the fact that today we still miss a generalised definition of financial cycles. General literature uses Minsky's financial instability hypothesis to define financial cycles in the form of the Minsky's cycle. Pioneering works of Borio and Drehmann (2011), Drehmann et al. (2012, 2013) define financial cycles as long swings in financial conditions (credit and assets price). A large body of research focuses on finding an optimal method for measuring financial cycles (Schüler et al., 2015; Strohsal et al., 2019; Hiebert et al., 2014; Rünstler \& Vlekke, 2018; Skare \& Rochon, 2020).

In this paper, we use quarterly big data for the United Kingdom, the United States, Japan and China from Q1 2004 Q1 2019. We use web-based indicators from the Google trends, financial market data (house price index and credit volume, share in the GDP), long- interest rates on the 10-year government treasury bond, consumer and business confidence index and share price index. Using frequency domain time-series methods singular (SSA) and multichannel singular spectrum analysis (MSSA), we test the impact of big data statistics on financial cycles forecasting. Our results show that policymakers can get better macro-aggregates to use in financial cycles forecasting and thus better forecasting accuracy and validity. Assuring better information support and prognosis on financial cycles can help economic agents in the decision-making process on financial markets. In the same time, using relevant micro-financial data improve the relevance of macro-financial aggregates. Financial cycles reflect fluctuations in macro-financial aggregates. Thus, more precise measurement and identification of financial cycles support central bank policies meeting information needs for price and macro-financial stability. Comparing the forecasting results in this study, we can see that the results of the Diebold and Mariano (1995) test support the hypothesis that more accurate forecasting of the financial cycles can be obtained using financial big data. Big data financial cycles can serve the purpose of developing early warning signals of financial distress as a financial crisis predictor. Since more contemporary studies show financial conditions articulate real economic activity dynamics and thus business cycles, understanding the true nature of the financial cycles is of crucial importance for unravelling business cycles. Our study results in financial big data can have an essential role in this attempt. 
We structure the rest of the paper: after the introduction on financial cycles and big data link, literature with an interest in financial big data is presented. In section three, we describe data used in the study and method we apply to get the results on tested hypothesis. We present empirical results discussion and implications in section four, while part five bring up conclusions on the role and importance of financial big data for financial and economic stability analysis.

\section{Financial big data implication for financial cycles: a review}

The literature on the importance of financial big data for financial cycles measurement is novel and scarce. Hassani and Silva (2015) offer a review of the pros and cons of using big data for the purpose of forecasting. Alessi et al. (2009) study show large macroeconomic and financial data improve forecast performance in finance and economics. Altissimo et al. (2010) provide evidence of using big data to improve the forecast accuracy when using band-pass filters. Using data from the google trends in the study of Choi and Varian (2012) improve the forecasting prediction for economic indicators. Gupta et al. (2014) forecast employment using classical and Bayesian methods applied to eight sectors for the US economy with 143 monthly series. Forecast model using big data information outperform other models in forecast accuracy.

Large data sets (big data) availability is essential but not a sufficient condition for improving forecast accuracy or model predictions (Silver, 2012). Bańbura and Modugno (2014) find forecasting with large datasets more complex for signal extraction.

To fully understand financial cycles we need big data on the micro and macro-level (Vychytilová et al., 2019). Wibisono et al. (2019) define big data as a large volume of information resulting from the web, financial, administrative and commercial records. They find the financial big data phenomenon as a new opportunity for decision-making process improvement (complete, immediate and granural information adding new value to 'traditional' macroeconomic indicators). Therefore, big data analytics and artificial intelligence offer new opportunities to central banks and economic agents on the financial markets (Huarng et al., 2019). Opportunities but challenges as well (resources availability, unresolved changing decision-making processes, best policy introduction). Subrahmanyam (2019) review the body of literature on big data in the finance application. Big data application in finance ranges from the basic application as in (Tetlock, 2007) to complex (Tetlock et al., 2008). According to their study, text analysis in the financial press capture hard-to-quantify aspects of firms' fundamental supporting robust low firm' earning forecasting (Phillips, 2019). Big data based on quantifying language application can help to improve methods for measuring firms' fundamentals or forecast market trends. Big data in finance also help to fill in the gap between qualitative and quantitative data application (Huang, 2018). His study results show big data on consumers opinions (from Amazon. com) when used provide a more robust prediction about firms' cash flow and stock pricing. Chordia et al. (2018) show that using newsfeed data on macroeconomic conditions only minorly increase profits from fast trading. According to the study of Fan et al. (2012), using high-frequency financial data improve the efficiency and stability of portfolio selection. The literature on big data application for 
policy purpose is much more limited (Tissot, 2019). He lists the advantages and disadvantages of using financial big data to obtain macro-relevant micro information, better macro aggregates to improve policy design and assessment.

Financial big data opened its way to portfolio and decision making (Šestanović et al., 2018) processes on the micro-level and it is just moving (slowly) on the macro-level (central banks and financial authorities).

\section{Dataset and stylized facts on financial cycles in the UK, USA, Japan and China 2005-2019}

Our paper is first to combine financial big data for financial cycles predictions. We follow Wibisono et al. (2019) definition of financial big data and use the following variables:

- HPI $=$ Residential property prices selected - Real - Index, $2010=100$, Bank for International Settlements;

- CRS = Credit to Private non-financial sector from all sectors at Market value - Percentage of GDP - Adjusted for breaks, Bank for International Settlements;

- CRT = Credit to Private non-financial sector from all sectors at Market value - US dollar - Adjusted for breaks, Bank for International Settlements;

- SHARE = OECD (2019), Share prices (indicator). doi: 10.1787/6ad82f42-en (Accessed on 29 October 2019), $2015=100$;

- CCI = OECD (2019), Consumer confidence index (CCI) (indicator). doi: 10.1787/46434d78-en (Accessed on 30 October 2019), Long-term average $=100$;

- BCI = OECD (2019), Business confidence index (BCI) (indicator). doi: 10.1787/3092dc4f-en (Accessed on 30 October 2019), Long-average = 100;

- WEB = Google trends data on a financial crisis search term (Numbers represent search interest relative to the highest point on the chart for the region and time. A value of 100 is the peak popularity for the term. A value of 50 means that the term is half as popular. A score of 0 means there was not enough data for this term);

- OECD (2019), Long-term interest rates (indicator). doi: 10.1787/662d712c-en (Accessed on 29 October 2019), Long-term interest rates refer to government bonds maturing in ten years. For China we use China 10-Year Bond Yield government bonds maturing in ten years, investing.com (2019), https://www.investing.com/rates-bonds/ china-10-year-bond-yield-historical-data.

We use data for the United Kingdom (UK), United States (US), Japan (Jap) and China (CHI) from Q1 2004 to Q1 2019 (quarterly data). Previous studies on financial cycles use data on residential property prices, credits to private non-financial sectors and credits to private non-financial sector's share in the GDP (gross domestic product). Facing limited data availability on financial conditions and web we had to choose between longer time series and a variety of data sources. For the purpose of testing the importance of financial big data in financial cycles prediction, we use data from various sources: web-based indicators - social networks (financial crisis search term importance), financial market data (share prices, residential property prices, credits), administrative data (consumer confidence index, business confidence index, long-term interest rates), commercial data sets (government bonds yields). 
To measure financial cycle components, we use spectral analysis techniques - Eviews 10.0 adds-in for Spectral analysis (Ronderos, 2014). Prior to analysis, we normalize and centre all the series for the purpose of eliminating noise in the series. Since normalization procedure increases the possibility of spurious cycles existence in the series, we apply (Ronderos, 2014) significant pass filter (SPF) method of the form:

$$
F_{t}=\sum_{k=0}^{n / 2}\left[A_{k} \cos \left(\omega_{k} t\right)+B_{k} \sin \left(\omega_{k} t\right)\right],
$$

with $F_{t}$ - filtered series, $\left(A_{k}=a_{k}\right),\left(B_{k}=b_{k}\right)$ ordinate $\left(I\left(\omega_{k}\right)\right)$ to test statistical significance of the deterministic component in the spectrum.

To test if the isolated deterministic cycles are statistically significant we use the following set of tests (Ronderos, 2014; Wei, 1994; Whittle, 1952, p. 309; Fisher, 1929, pp. 54-59; Bartlett, 1954, pp. 296-298):

$$
\begin{aligned}
& \text { F test } F=\frac{\left(a_{k}^{2}+b_{k}^{2}\right) / v_{1}}{\sum_{j=1, j \neq k}^{n / 2}\left(a_{j}^{2}+b_{j}^{2}\right) / v_{2}} \sim F\left(v_{1}, v_{2}\right) . \\
& \text { Fisher test } T=\frac{\max \left\{I\left(\omega_{k}\right)\right\}}{\sum_{k=1}^{n / 2} I\left(\omega_{k}\right)} . \\
& \text { Whittle test } T_{2}=\frac{I^{(2)}\left(\omega_{(2)}\right)}{\sum_{k=1}^{n / 2} I\left(\omega_{k}\right)-I^{(1)}\left(\omega_{(1)}\right)} .
\end{aligned}
$$

Figure 1 shows a spectrum for the three financial series - HPI $=$ Residential property prices selected, CRS $=$ Credit to Private non-financial sector from all sectors at Market value - Percentage of GDP, CRT $=$ Credit to Private non-financial sector from all sectors at Market value - US dollar in the UK. The shaded area shows deterministic cycles between 0.016 and 0.032 frequencies (cycle/time unit) corresponding to 61 and 31 quarters or 15 and 8 years period.

Figure 2 confirms the results we find for the UK. In the United States, all three financial series show the same behaviour as in the UK. As we can see from the Figure 2, the grey area shows the statistically significant component cycles which correspond to 8 and 15 years for the residential property prices, credit to private non-financial sectors and credit share in the GDP. Outside the area between 0.016 and 0.032 frequencies (cycle/time unit) corresponding to 61 and 31 quarters or 15 and 8 years period, we did not isolate important deterministic cycles.

Figure 3 shows more variability in the housing and financial markets in Japan. Although we can observe several possible deterministic cycles in the housing and financial markets in Japan statistical tests shows statistically significant cycles in the financial series are present within 8 and 15 years. Thus, results for Japan are in line with the one we observe for the UK and the US. F test, Fisher test and Whittle test confirm the statistical significance of the deterministic cycles between 8 to 15 years. 

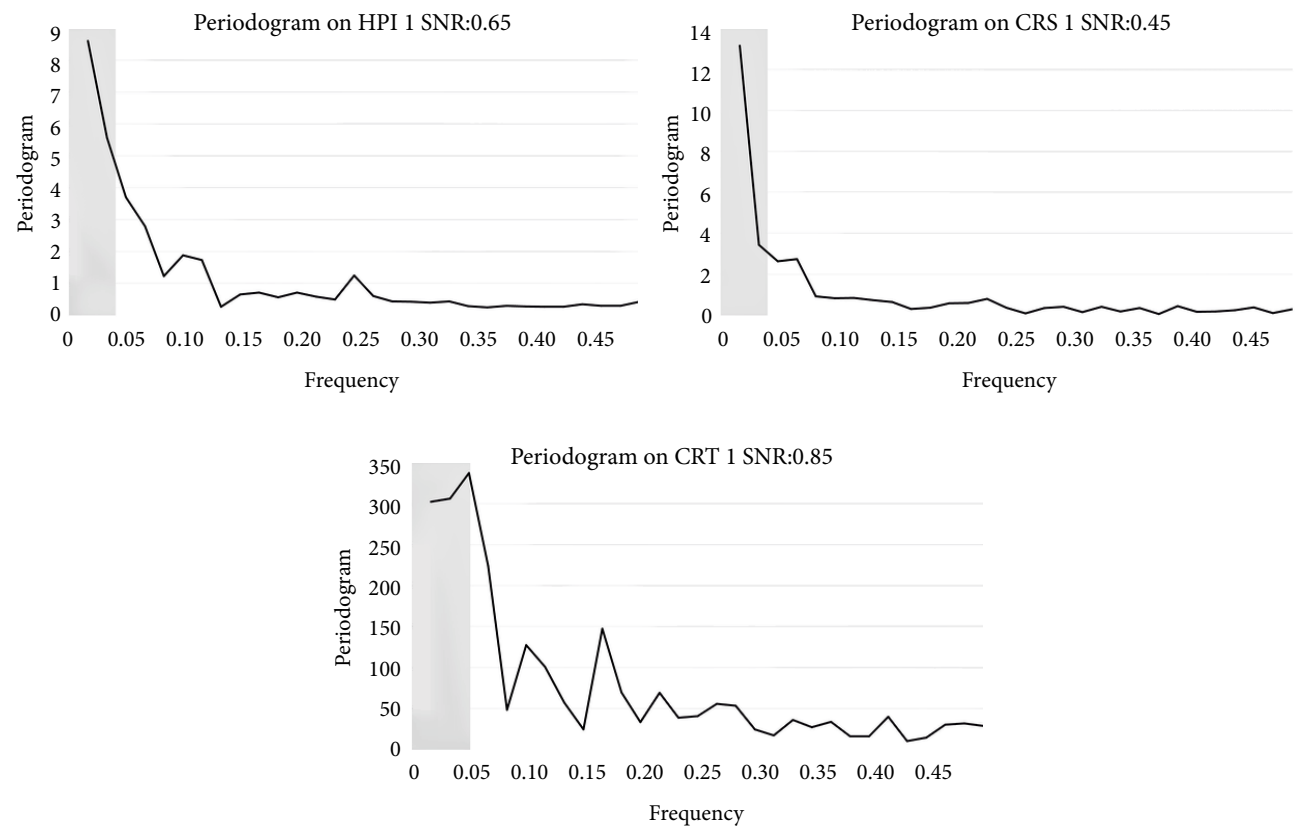

Figure 1. Spectrum of residential property prices, credit to private non-financial sector, credit share in the GDP in the UK Q1 2005 - Q1 2019 (source: authors' calculation)
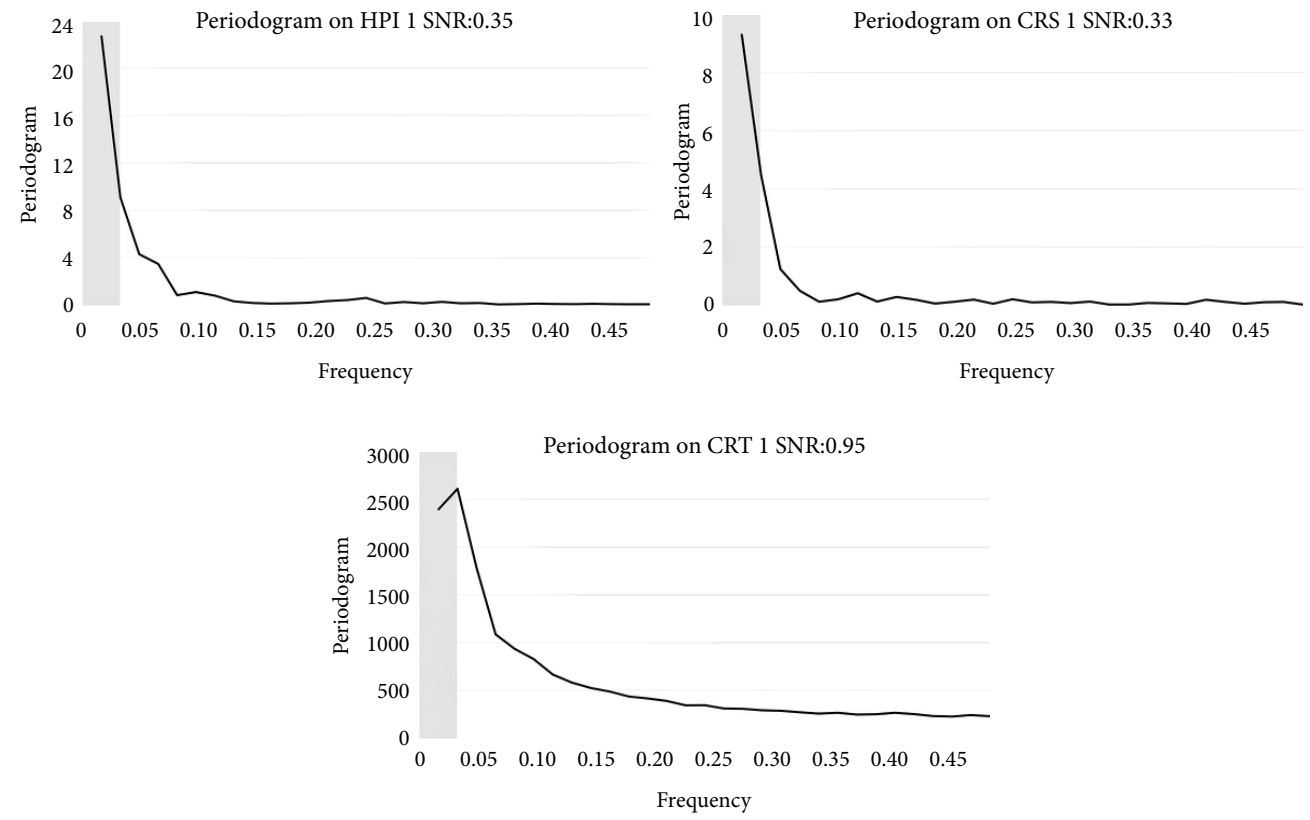

Figure 2. Spectrum of residential property prices, credit to private non-financial sector, credit share in the GDP in the USA Q1 2005 - Q1 2019 (source: authors' calculation) 

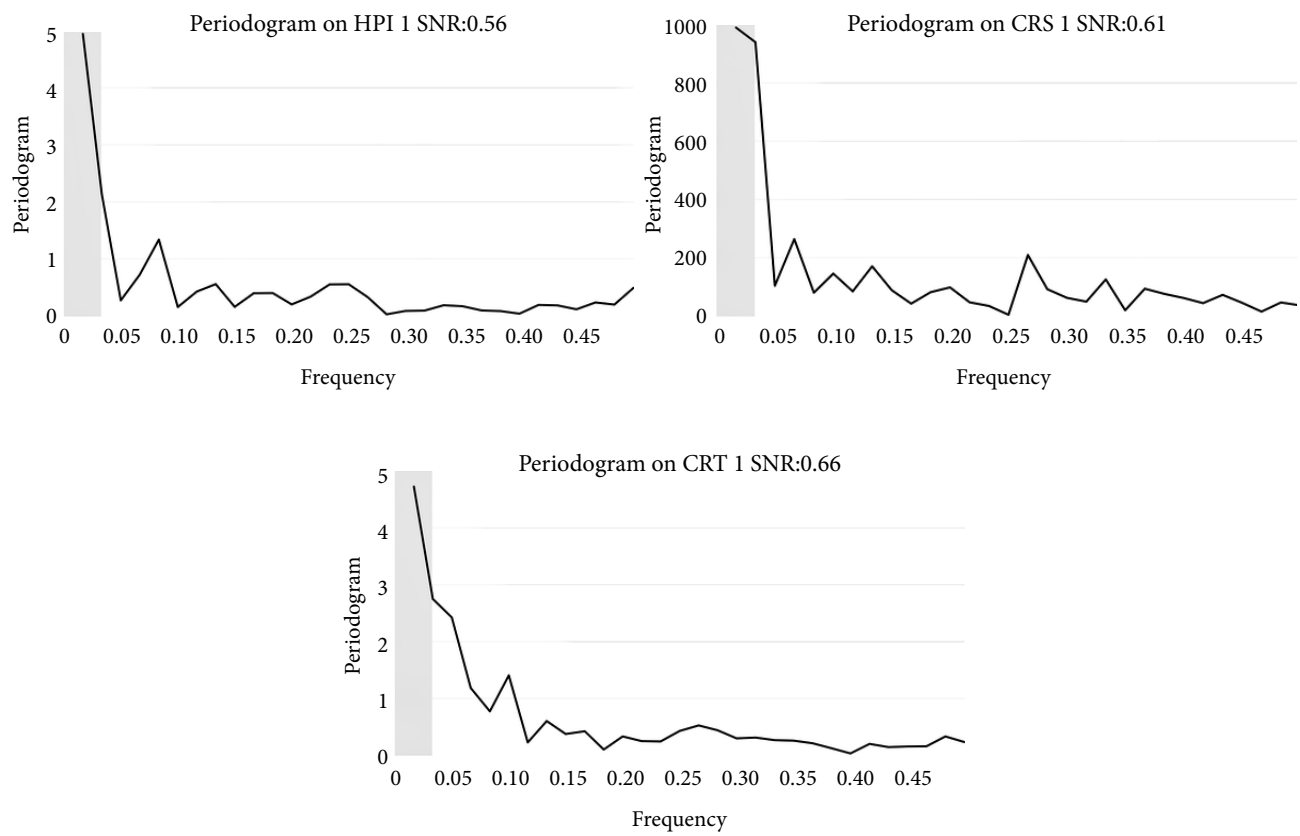

Figure 3. Spectrum of residential property prices, credit to private non-financial sector, credit share in the GDP in Japan Q1 2005 - Q1 2019 caption
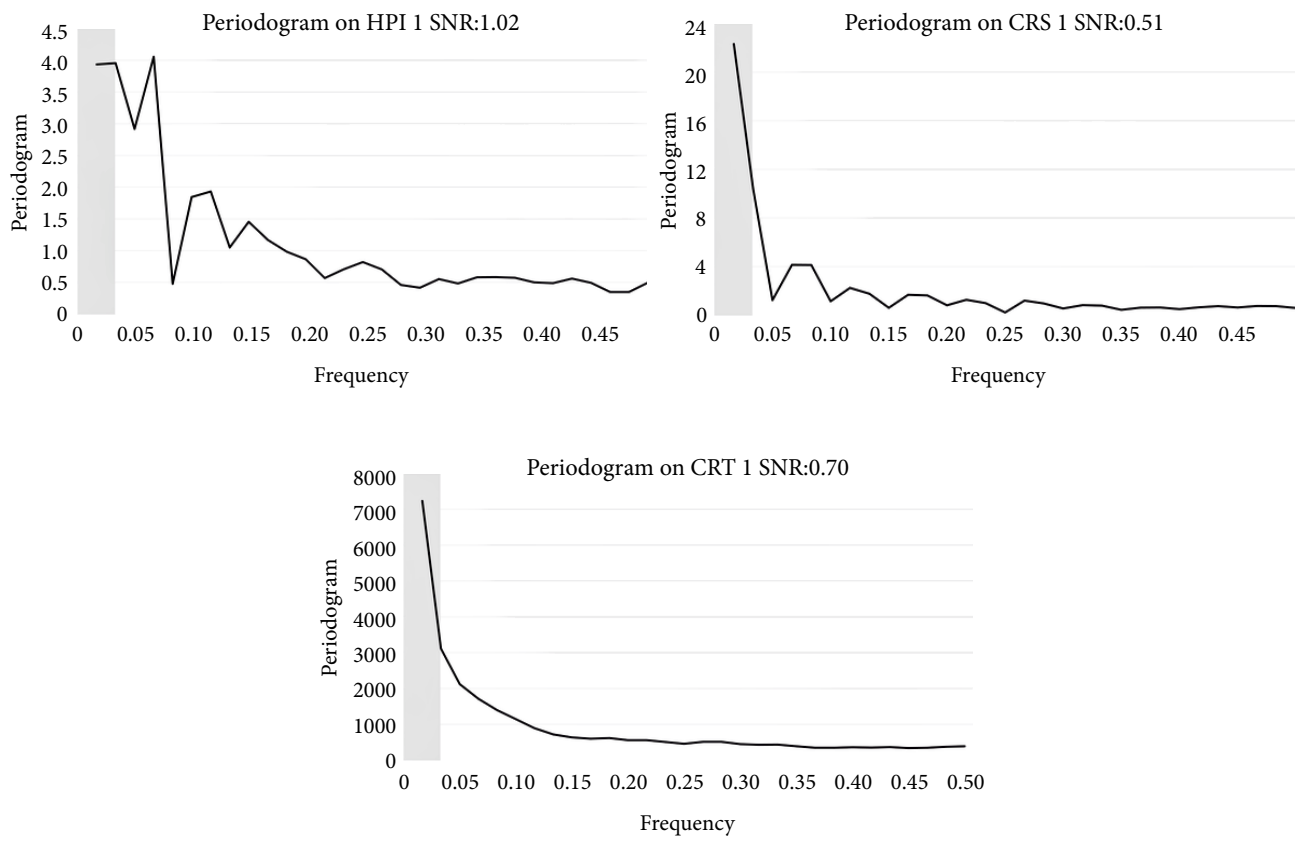

Figure 4. Spectrum of residential property prices, credit to private non-financial sector, credit share in the GDP in China Q1 2005 - Q1 2019 
Volatility on the housing and financial markets in China is more similar to the dynamics we find in Japan. Large volatility, as expected to be present, is visible on the housing market in China. We expect such price dynamics on the housing market because of the changes in the Hukou system (policy regulated migration from the countryside to the cities) having a direct influence on the demand for housing in China. It reflects housing demand dynamics in the credit demand (mortgage loans) that is observed in Figure 4 (graph on the right). Cyclical fluctuations both for housing prices and credit to the private non-financial sector is statistically significant for the cycle period between 8 to 15 years. The cyclical fluctuation on the credit market (\% share in the GDP) after testing for deterministic cycles also exhibits an 8 to 15 years pattern with smaller volatility compared to the volatility on the housing market and credit to a private non-financial sector (volume).

Deterministic cycle test results validate the results of the previous studies on financial cycles finding a cyclical pattern in the financial time series ranging from 8 to 15 years on average for the UK, USA, Japan and China. After the financial cycles identification by the means of spectral analysis, we proceed by testing if Big data can help to improve the financial cycles forecasting.

\section{Using financial big data for improving financial cycles forecasting accuracy}

To test the hypothesis that financial big data improve financial cycles forecasting we proceed in several steps. First by the means of the singular spectrum analysis (SSA) of the form Vautard et al. (1992, pp. 95-126):

$$
c_{i j}=\frac{1}{N-|i-j|} \sum_{t=1}^{N-|i-j|} X(t) X(t+|i-j|),
$$

where: $c_{i j}$ - lag covariance matrix; $N$ - number of data points in time series; $i, j$ - time indices; $t$ - continuous time $t \in \mathrm{R} ; x(t)$ - observed time series, using data on housing prices and credits we isolate financial cycles for the UK, USA, Japan and China. Following on the isolate (SSA) components, we apply a linear recurrent formula for (SSA) forecasting. As a final outcome, we get an R-forecasting (SSA forecasting method) for residential property prices, credit to the private non-financial sector, credit share in the GDP over the eight quarters (2017 Q2 - 2019 Q1).

To check if financial big data can help in raising the financial cycles forecasting efficiency, we apply

(MSSA) of the form (Ghil et al., 2002) on residential property prices, credit to private non-financial sector, credit share in the GDP:

$$
\begin{aligned}
& \left(C_{l, l^{\prime}}\right)_{i, j}=\frac{1}{\bar{N}} \sum_{t=\min \left(1,1,1^{\prime}+i-j\right)}^{\max (N+i-j)} x_{l}(t) x_{l^{\prime}}(t+i-j), \\
& \tilde{N}=\min \{N, N+i-j\}-\max \{1,1+i-j\}+1,
\end{aligned}
$$

where: $c_{i j}$ - lag covariance matrix; $c l, l_{j}$ - lag cross-covariance matrix; $N$ - number of data points in a time series; $i, j$ - indices of time; $t$ - continuous time $t \in R ; x(t)$ - L-channel vector time series. 
As with (SSA), using the R-forecasting (MSSA forecasting method) we now get the (MSSA) forecasting results (forecasting including financial big data) for the residential property prices, credit to private non-financial sector, credit share in the GDP over the period 2017 Q2 - 2019 Q1.

To test the improved accuracy (better forecasting results) we obtain when using financial big data we use the Diebold-Mariano test (Diebold \& Mariano, 1995; Diebold, 2015) of the form:

$$
D M_{12}=\frac{\bar{d}_{12}}{\hat{\sigma}_{\bar{d}_{12}}} \rightarrow N(0,1)
$$

where: $\bar{d}_{12}=\frac{1}{T} \sum_{t=1}^{T} d_{12 t}$ - sample means loss differential; $\hat{\sigma}_{\bar{d}_{12}}$ - consistent estimate of standard
deviation.

Diebold-Mariano test results confirm our hypothesis that financial big data improve forecasting accuracy for financial cycles (see Table 1 for the UK).

From the Table 1, we can see that various measures for forecast accuracy, (RMSE - rootmean-square error), (MAE - mean square error), (MAPE - mean absolute percentage error), (SMAPE - symmetric mean absolute percentage error) for the financial series in the UK from 2017 Q2 to 2019 Q1. The scores from Table 1 show that the (MSSA) forecasts (including financial big data) are superior to the (SSA) forecasts (not including financial big data). We can observe that forecasts we get using (MSSA) for the period 2017 Q2 - 2019 Q1 (out of the sample forecasts since we use a sample for the forecasting accuracy comparison from 2004 Q1 to 2017 Q1) for the residential property prices, credit to private non-financial sector, credit share in the GDP in the UK are far superior to the one we get using (SSA). Taking into account financial big data improves forecasting accuracy for financial series in the UK. Similar results we observe with the USA (see Table 2).

As Table 2 shows, forecast accuracy scores for residential property prices show (MSSA using financial big data) significantly increase. A significant increase in the forecast accuracy of (MSSA) also is present for the credit to private non-financial sector time-series data. Still statistically significant but with lower forecast accuracy in relation to the (MSSA) forecasts for the residential property prices and credit to the private non-financial sector is the forecast accuracy for the credit share in the GDP. We can conclude that statistical tests for forecast accuracy show financial time series (financial cycle components) can be better forecast when using financial big data in the USA.

For Japan (see Table 3), we can also observe that forecast accuracy for the financial cycle components increase if we use financial big data in the forecast process. Statistical test (forecast accuracy scores) show that we can make more accurate forecasts for residential property prices in Japan using financial big data. The same holds for the credit to private non-financial sector time series data with accuracy scores in favor of using (MSSA) for forecasting. We can notice a significant increase in the forecast accuracy for the credit share in the GDP time series data with residual errors being 2 to 3 times lower if we use financial big data and (MSSA) for forecasting.

Table 4 show forecast accuracy scores for the (SSA) and (MSSA) in forecasting financial cycle components in China. 
Table 1. Forecast Accuracy for the SSA, MSSA for Financial Series in the UK 2017 Q2 - 2019 Q1 (source: authors' calculation)

\begin{tabular}{|c|c|c|c|c|}
\hline & RMSE & MAE & MAPE & SMAPE \\
\hline SSA & 0.33 & 0.28 & 27.58 & 33.41 \\
\hline MSSA & 0.29 & 0.25 & 23.98 & 28.38 \\
\hline \multicolumn{5}{|c|}{ Residential property prices } \\
\hline SSA & 0.37 & 0.26 & 33.43 & 36.09 \\
\hline MSSA & 0.3 & 0.2 & 25.61 & 26.9 \\
\hline \multicolumn{6}{|c|}{ Credit to private non-financial sector } \\
\hline SSA & 0.44 & 0.39 & 289.35 & 164.75 \\
\hline MSSA & 0.33 & 0.27 & 239.18 & 145.67 \\
\hline
\end{tabular}

Table 2. Forecast accuracy for the SSA, MSSA for Financial Series in the USA 2017 Q2 - 2019 Q1 (source: authors' calculation)

\begin{tabular}{|c|c|c|c|c|}
\hline & RMSE & MAE & MAPE & SMAPE \\
\hline SSA & 0.16 & 0.14 & 26.22 & 31.03 \\
\hline MSSA & 0.1 & 0.08 & 17.85 & 18.47 \\
\hline \multicolumn{5}{|c|}{ Residential property prices } \\
\hline SSA & 0.46 & 0.38 & 60.29 & 101.11 \\
\hline MSSA & 0.34 & 0.29 & 46.19 & 67.66 \\
\hline \multicolumn{7}{|c|}{ Credit to private non-financial sector } \\
\hline SSA & 0.29 & 0.25 & 14.81 & 15.2 \\
\hline MSSA & 0.25 & 0.22 & 13.63 & 13.42 \\
\hline
\end{tabular}

Table 3. Forecast accuracy for the SSA, MSSA for Financial Series in Japan 2017 Q2 - 2019 Q1 (source: authors' calculation)

\begin{tabular}{|c|c|c|c|c|}
\hline & RMSE & MAE & MAPE & SMAPE \\
\hline SSA & 0.38 & 0.28 & 59.77 & 34.64 \\
\hline MSSA & 0.32 & 0.24 & 54.01 & 31.7 \\
\hline \multicolumn{5}{|c|}{ Residential property prices } \\
\hline SSA & 0.4 & 0.34 & 52.18 & 74.63 \\
\hline MSSA & 0.3 & 0.26 & 114.02 & 52.45 \\
\hline SSA & 0.73 & 0.66 & 256.54 & 160.17 \\
\hline MSSA & $0.26 \quad 0.24$ & 74.18 & 104.32 \\
\hline
\end{tabular}


Table 4. Forecast accuracy for the SSA, MSSA for Financial Series in China 2017 Q2 - 2019 Q1 (source: authors' calculation)

\begin{tabular}{|c|c|c|c|c|}
\hline & RMSE & MAE & MAPE & SMAPE \\
\hline SSA & 1.51 & 1.2 & 64.79 & 111.03 \\
\hline MSSA & 0.81 & 0.7 & 39.62 & 51.4 \\
\hline \multicolumn{5}{|c|}{ Residential property prices } \\
\hline SSA & 0.61 & 0.53 & 31.03 & 33.03 \\
\hline MSSA & 0.46 & 0.44 & 28.35 & 26.27 \\
\hline SSA & 0.25 & 0.19 & 12.01 & 11.42 \\
\hline MSSA & 0.24 & 0.18 & 12.05 & 11.04 \\
\hline
\end{tabular}

Forecast accuracy for residential property prices in China improves significantly when we use financial big data for forecasting in relation to the results we get without these data. We can see from Table 4 that all forecast accuracy scores prove the validity of this statement. For the credit to private non-financial sector time series forecast accuracy when using financial big data improves as well (on a smaller scale when compared to the forecast accuracy for the residential property prices). The same result holds for the credit share in the GDP series with forecast accuracy using financial big data (MSSA) outperform the forecast produces by (SSA) without financial big data.

Forecast accuracy tests and scores show on the sample for the UK, USA, Japan and China (four growth potential economies different in structure and size) that financial big data can significantly improve forecasting of the financial cycle components (residential property prices, credit to private non-financial sector and credit share in the GDP).

\section{Conclusions}

This study has showed that using financial big data significantly improve the forecast accuracy for financial cycle components (residential property prices, credit to private nonfinancial sector and credit share in the GDP). The forecast test results show on the data for the UK, USA, Japan and China that inclusion of the financial big data significantly (on the level from $30 \%$ to four times) improves forecast accuracy for financial cycle components. This is the first study to examine the role of the financial big data in the study of financial cycles. Inclusion of the financial big data in the various model (time series, frequency domain, the turning point, multiple cycles) aiming at measuring the exact length of financial cycles. Such a knowledge (financial big data) will help to better understand the mechanism behind financial cycles, methods and tools for their monitoring and forecasting. Policymakers and central banks motivated to mitigate the risks of the financial cycles will find this knowledge useful in building new models for financial cycles detection and forecasting.

The lack of studies using financial big data for measuring and forecasting financial cycles may show that policymakers, practitioners and academics do not find the link between fi- 
nancial big data and financial cycles important or promising. Another plausible explanation is that financial big data from their point of view serve the purpose of forecasting financial conditions (Subrahmanyam, 2019), market portfolio selection (Fan et al., 2012, pp. 412-428), equity prices forecasting, mitigating risks and volatility on the financial markets. Although all these issues are important for financial studies (Alessi et al., 2009), no previous study on the link between financial cycles and big data exists.

Our analysis suggests research on financial cycles can be significantly improved if the financial big data are used in the research. The Diebold-Mariano test result confirms the validity of the hypothesis that financial big data are important for measurement and forecasting of the financial cycles. Our findings bring important insight to the policymakers and financial practitioners and academic community and interested in monitoring and studying the financial cycles and their role in financial crisis and thus business cycles.

An important strength of our study is that we use several financial big data (supporting the research of (Tetlock, 2007) for a sample of four countries reporting several forecast accuracy scores and Diebold-Mariano test results. However, since financial big data are not available in a long time series form, we use a limited-time series sample. Research results should be validated for a larger sample of countries that could bring additional insight into the research question.

In our sample, all forecast accuracy statistics and Diebold-Mariano test results put forward a single, statistically validated conclusion - financial big data are an important element for studying financial cycles. We encourage further research to distinguish between financial cycles studies using financial big data; identify the most important sources of such data (statistical robustness) and become familiar with developing new study models on financial cycles using financial big data.

\section{Acknowledgements}

We are grateful to the editor and two anonymous referees for valuable suggestions and feedback.

\section{Funding}

The project is financed within the framework of the program of the Minister of Science and Higher Education under the name "Regional Excellence Initiative" in the years 2019-2022; project number 001/RID/2018/19; the amount of financing PLN 10,684,000.00.

\section{References}

Alessi, L., Barigozzi, M., \& Capasso, M. (2009). Forecasting large datasets with conditionally heteroskedastic dynamic common factors (Working paper No. 1115). European Central Bank.

Altissimo, F., Cristadoro, R., Forni, M., Lippi, M., \& Veronese, G. (2010). New Eurocoin: Tracking economic growth in real time. Review of Economics and Statistics, 92(4), 1024-1034.

https://doi.org/10.1162/REST_a_00045 
Bartlett, M. S. (1954). A note on the multiplying factors for various $\$ 2$ approximations. Journal of the Royal Statistical Society. Series B (Methodological), 16(2), 296-298. https://doi.org/10.1111/j.2517-6161.1954.tb00174.x

Bańbura, M., \& Modugno, M. (2014). Maximum likelihood estimation of factor models on datasets with arbitrary pattern of missing data. Journal of Applied Econometrics, 29(1), 133-160. https://doi.org/10.1002/jae.2306

Borio, C., \& Drehmann, M. (2011). Financial instability and macroeconomics: Bridging the Gulf. In The International Financial Crisis (pp. 237-268). World Scientific Publishing Co. https://doi.org/10.1142/9789814322096_0017

Choi, H., \& Varian, H. (2012). Predicting the present with Google Trends. Economic Record, 88(1), 2-9. https://doi.org/10.1111/j.1475-4932.2012.00809.x

Chordia, T., Green, T. C., \& Kottimukkalur, B. (2018). Rent seeking by low-latency traders: Evidence from trading on macroeconomic announcements. The Review of Financial Studies, 31(12), 46504687. https://doi.org/10.1093/rfs/hhy025

Diebold, F. X. (2015). Comparing predictive accuracy, twenty years later: A personal perspective on the use and abuse of Diebold-Mariano Tests. Journal of Business and Economic Statistics. https://doi.org/10.1080/07350015.2014.983236

Diebold, F. X., \& Mariano, R. S. (1995). Comparing predictive accuracy. Journal of Business and Economic Statistics. https://doi.org/10.1080/07350015.1995.10524599

Drehmann, M., Borio, C., \& Tsatsaronis, K. (2012). Characterising the financial cycle: Don't lose sight of the medium term! (BIS Working Papers No. 380, pp. 1-38).

Drehmann, M., Borio, C., \& Tsatsaronis, K. (2013). Can we identify the financial cycle? In The role of central banks in financial stability (pp. 131-156). World Scientific Publishing Co. https://doi.org/10.1142/9789814449922_0007

Fan, J., Li, Y., \& Yu, K. (2012). Vast volatility matrix estimation using high-frequency data for portfolio selection. Journal of the American Statistical Association, 107(497), 412-428. https://doi.org/10.1080/01621459.2012.656041

Fisher, R. A. (1929). Tests of significance in harmonic analysis. Proceedings of the Royal Society of London. Series A, Containing Papers of a Mathematical and Physical Character, 125(796), 54-59. https://doi.org/10.1098/rspa.1929.0151

Ghil, M., Allen, M. R., Dettinger, M. D., Ide, K., Kondrashov, D., Mann, M. E., Robertson, A. W., Saunders, A., Tian, Y., Varadi, F., \& Yiou, P. (2002). Advanced spectral methods for climatic time series, Reviews of Geophysics, 40(1), 3-1-3-41. https://doi.org/10.1029/2000RG000092

Gupta, R., Kabundi, A., Miller, S. M., \& Uwilingiye, J. (2014). Using large data sets to forecast sectoral employment. Statistical Methods \& Applications, 23(2), 229-264.

https://doi.org/10.1007/s10260-013-0243-6

Hassani, H., \& Silva, E. S. (2015). Forecasting with Big Data: A review. Annals of Data Science, 2, 5-19. https://doi.org/10.1007/s40745-015-0029-9

Hiebert, P., Klaus, B., Peltonen, T. A., Schüler, Y. S., \& Welz, P. (2014). Capturing the financial cycle in euro area countries. ECB Financial Stability Review, (November), 109-117.

Huang, J. (2018). The customer knows best: The investment value of consumer opinions. Journal of Financial Economics, 128(1), 164-182. https://doi.org/10.1016/j.jfineco.2018.02.001

Huarng, K. H., Yu, T. H.-K., Rodriguez-Garcia, M. (2019). Qualitative analysis of housing demand using Google trends data, Economic Research-Ekonomska Istraživanja. https://doi.org/10.1080/1331677X.2018.1547205

Investing.com. (2019). China 10-year bond yield. https://www.investing.com/rates-bonds/china-10-year-bond-yield-historical-data 
Keynes, J. M. (1936). The general theory of employment, interest and money. Macmillan. https://search. library.wisc.edu/catalog/999623618402121

Milburn, O. (2007). The book of the young master of accountancy: An ancient Chinese economics text. Journal of the Economic and Social History of the Orient, 50(1), 19-40. https://doi.org/10.1163/156852007780324002

Minsky, H. P. (1963). Can 'it' happen aggain? In D. Carson (Ed.), Banking and monetary studies. Homewood.

Minsky, H. P. (1975). John Maynard Keynes. Columbia University Press. https://doi.org/10.1007/978-1-349-02679-1

OECD. (2019). Main economic indicators. https://www.oecd-ilibrary.org/economics/data/main-economic-indicators_mei-data-en

Phillips, A. W. (1962). Employment, inflation and growth. Economica, 29(113), 1-16. https://doi.org/10.1111/j.1468-0335.1962.tb00001.x

Phillips, F. (2019). Does complexity belong inside the firm, or out? Economic Research-Ekonomska Istraživanja. https://doi.org/10.1080/1331677X.2019.1625796

Ronderos, N. (2014). Spectral analysis using EViews. https://www.eviews.com/Addins/SpectralAnalysis. aipz

Rünstler, G., \& Vlekke, M. (2018). Business and financial cycles: an unobserved components models perspective. Journal of Applied Econometrics, 33(2), 212-226. https://doi.org/10.1002/jae.2604

Schumpeter, J. A. (1939). Business cycles: a theoretical, historical, and statistical analysis of the capitalist process. McGraw-Hill.

Schüler, Y. S., Hiebert, P. P., \& Peltonen, T. A. (2015). Characterising the financial cycle: a multivariate and time-varying approach (ECB Working Paper No. 1846). European Central Bank.

Silver, N. (2012). The signal and the noise: Why so many predictions fail-but some don't. Penguin Publishing Group.

Skare, M., \& Porada-Rochoń, M. (2020). Multi-channel Singular-Spectrum Analysis (MSSA) of financial cycles in ten developed economies 1970-2018. Journal of Business Research, 112, 567-575. https://doi.org/10.1016/j.jbusres.2019.10.047

Strohsal, T., Proaño, C. R., \& Wolters, J. (2019). Characterizing the financial cycle: Evidence from a frequency domain analysis. Journal of Banking and Finance, 106, 568-591.

https://doi.org/10.1016/j.jbankfin.2019.06.010

Subrahmanyam, A. (2019). Big data in finance: Evidence and challenges. Borsa Istanbul Review, 19(4), 283-287. https://doi.org/10.1016/j.bir.2019.07.007

Šestanović, T., Arnerić, J., \& Aljinović, Z. (2018). Non-structural approach to implied moments extraction. Economic Research-Ekonomska Istraživanja, 31(1), 1923-1939. https://doi.org/10.1080/1331677X.2018.1530607

Tetlock, P. C. (2007). Giving content to investor sentiment: The role of media in the stock market. The Journal of Finance, 62(3), 1139-1168. https://doi.org/10.1111/j.1540-6261.2007.01232.x

Tetlock, P. C., Saar-Tsechansky, M., \& Macskassy, S. (2008). More than words: Quantifying language to measure firms' fundamentals. Journal of Finance, 63(3), 1437-1467. https://doi.org/10.1111/j.1540-6261.2008.01362.x

Tissot, B. (2019). Financial big data and policy work: opportunities and challenges (pp. 1-21). Eurostat.

Vautard, R., Yiou, P., \& Ghil, M. (1992). Singular-spectrum analysis: A toolkit for short, noisy chaotic signals. Physica D: Nonlinear Phenomena, 58(1-4), 95-126.

https://doi.org/10.1016/0167-2789(92)90103-T 
Vychytilová, J., Pavelková, D., Pham, H., \& Urbánek, T. (2019). Macroeconomic factors explaining stock volatility: Multi-country empirical evidence from the auto industry. Economic Research-Ekonomska Istraživanja, 32(1), 3327-3341. https://doi.org/10.1080/1331677X.2019.1661003

Whittle, P. (1952). Tests of fit in time series. Biometrika, 39(3/4), 309-318. https://doi.org/10.2307/2334027

Wibisono, O., Ari, H. D., Widjanarti, A., Zulen, A. A., \& Tissot, B. (2019). The use of big data analytics and artificial intelligence in central banking (IFC Bulletin No. 50). Irving Fisher Committee on Central Bank Statistics.

Wei, W. W. S. (1994). Time series analysis. Univariate and multivariate methods. Addison Wesley. 